\title{
La identidad personal del emigrante ecuatoriano representado en cuentos publicados entre 1981 y 2014
}

\section{The Personal Identity of the Ecuadorian Emigrant Represented \\ in Short Stories Published between 1981 and 2014}

\author{
Yovany SALAzAR EsTrada [ysalazarec2002@yahoo.es] \\ Universidad Nacional de Loja, Ecuador \\ MarCelo León Castro [marceloleon11@hotmail.com] \\ Universidad Nacional de Loja, Ecuador
}

\begin{abstract}
RESUMEN
El propósito del artículo es analizar la identidad personal del emigrante ecuatoriano representado en los cuentos publicados entre 1981 y el 2014. Con fundamento en algunas perspectivas teóricas ubicadas en el ámbito de las ciencias sociales y humanas (filosofía, psicología, sociología), que abordan el tema de la identidad personal, se concluye que existe una compleja pero muy fecunda representación de este tipo de identidad en las obras de narrativa breve seleccionadas como objeto de estudio. Para la presentación del ensayo analítico se organiza su contenido distribuido en cinco acápites, en los que se fundamenta, problematiza, ejemplifica y analiza la recreación literaria de los siguientes aspectos: la identidad personal de los emigrantes ecuatorianos, que fluctúa entre la ambivalencia, la búsqueda permanente y la fugacidad en las relaciones amorosas que establecen en los países de destino; la crisis de identidad personal del sujeto emigrante; las identidades múltiples; los cambios, de orden físico y mental, que genera el proceso emigratorio en sus protagonistas; y, la metamorfosis de los emigrantes ecuatorianos, que evidencian cambios radicales en el cuerpo y en la psiquis, a raíz de la salida del país de origen.
\end{abstract}

\section{Palabras Clave}

Cambios identitarios; crisis de identidad; cuento ecuatoriano y emigración

\begin{abstract}
The purpose of this article is to analyze the personal identity of Ecuadorian immigrant represented in short stories published between 1981 and 2014. Based on some theoretical perspectives located in the field of sciences social and humanities (philosophy, psychology, sociology), which address the issue of personal identity, it is concluded that there is a complex but very fruitful representation of this kind of identity in the literary works of short fiction selected as the object of study. For the presentation of analytical essays its contents is organized and distributed in five sections, on which it is based, problematizes, exemplifies and analyzes the literary recreation of the following aspects: the personal identity of Ecuadorian immigrants, which is ranging from ambivalence, the permanent search and transience in romantic relationships established in
\end{abstract}


countries of destination; crisis of personal identity of emigrants; multiple identities; changes, physical and mental order, which generates the emigration process in its protagonists; and the metamorphosis of Ecuadorian immigrants, who show radical changes in the body and the psyche, all of these caused by the leaving of the country of origin.

\section{KEYWORDS}

Changes of identity; crisis of identity; Ecuadorian short story and emigration

RECIBIDO 2018-04-09; ACEPTADO 2018-10-25

\section{La identidad personal de los emigrantes ecuatorianos}

La identidad personal constituye el ensamble de rasgos "por los que uno siente que es el mismo, en este lugar y este tiempo, tal como en aquel tiempo y en aquel lugar pasados o futuros; es aquello por lo cual se es identificado" (Roca 2003: 206). Desde esta misma línea de pensamiento, para otros autores, la identidad personal alude al "conjunto de signos procedentes de códigos de la más variada índole -psicológicos, éticos, políticos, religiosos, económicos, históricos, biológicos, geográficos, sociales, etcétera-” (Donoso 1998: 93), a los que se puede agregar una serie de rasgos externos, la mayoría de ellos, muy visibles, como: color de la piel o de los ojos, estatura, contextura física, sexo, género, estatus social, nivel económico, cultural o educativo.

El complejo proceso de permanente construcción, reconstrucción, cambio y transformación de la identidad personal de los emigrantes ecuatorianos tiene formas similares de manifestarse a las del resto de personas; sin embargo, evidencia, también, particulares rasgos característicos y formas de expresión que los diferencian e identifican, tanto en relación con el resto de connacionales que permanecen en el país de origen como de los nativos de los Estados nacionales de destino, conforme se desarrollará en los tres acápites subsiguientes (cf. Salazar 2016: 356-363).

\subsection{La ambivalencia de los emigrantes}

Con el propósito de acercarse a la identidad personal de los emigrantes internacionales resulta pertinente recordar el criterio de los psicoanalistas argentinos León y Rebeca Grinberg, para quienes con la emigración devienen enormes cambios que ponen en riesgo hasta la propia identidad de sus protagonistas, proceso en el cual se pierde una serie de aspectos, incluidos los elementos más preciados que tiene un individuo antes de abandonar la tierra de origen: "personas, cosas, lugares, idioma, cultura, costumbres, clima, a veces profesión y medio social o económico, etcétera, a todos los cuales están ligados recuerdos e intensos afectos, como así también están expuestos a la pérdida de partes del self y los vínculos correspondientes a esos objetos" (Grinberg 1996: 19).

A consecuencia de estos cambios, la identidad personal del sujeto emigrante se caracteriza por su carácter ambivalente, al pertenecer a dos mundos y vivir en permanente tensión entre ellos. Regresar al país de origen es un proyecto que no pierde vigencia; sin embargo, el deseo por ar- 
raigar en el lugar de destino también se abre paso, de allí la permanente ambivalencia, "en lo real compañeros que luchan por la supervivencia [...], en lo imaginario dos polos: en el origen, la familia que espera y depositó sus expectativas de cambio en él; en la meta, ilusiones y miedo ante un mundo desconocido al que enfrentarse" (Sanfeliu 2010: 77-79).

En estas complejas circunstancias, desde la perspectiva de los protagonistas del desplazamiento físico originado en el Ecuador, los cambios bruscos en las actividades cotidianas y las nuevas experiencias vitales les generan fuertes tensiones identitarias, a consecuencia de las cuales les asaltan una serie de interrogantes, propias del llamado Síndrome de Ulises que afecta a los emigrantes, como las siguientes: ¿Dónde estoy? ¿Qué va a ser de mi vida? ¿Por qué estoy aquí? ¿Por qué vine? ¿Por qué no estoy allá? (cf. Ampuero 2014: 29). Otras interrogantes que devienen una vez que se ha concretado el viaje emigratorio y que también topan el tema de la identidad personal del protagonista del movimiento poblacional son estas: “¿quién eres?, ¿cómo te sientes?, ¿quién quieres ser?, ¿cómo quieres ser?” (Aguirre 2014: 145).

Como una estrategia para responder a estas inquietudes y superar las dificultades que tienen que atravesar los emigrantes ecuatorianos sienten la necesidad de verbalizar y proclamar ante los nativos del país de destino, que se constituyen en los diferentes, los "otros", la identidad personal que los define como tales, conforme lo testimonia Diego Falconí Trávez, quien el primer día de clases en la Universidad Autónoma de Barcelona considera de vital importancia auto presentarse frente sus compañeros: "me llamo Diego y soy ecuatoriano. Soy abogado y estudié una cosa que se llama artes liberales. Ahora estoy en este doctorado y en España porque quiero cambiar mi rumbo hacia la literatura" (2014: 159). Otras señas de identidad personal y orientación sexual que este emigrante considera pertinente resaltar y hacer conocer a quienes conforman el nuevo entorno social, en el que le corresponde desenvolverse, son las siguientes: "hablo con voz gruesa, controlo mi cuerpo apropiadamente y no me muestro (muy) amanerado [...]. La performatividad en este escrito, ahora mismo, me sirve para explicar cómo mi ecuatorianidad se adhería a mi cuerpo de hombre, de mestizo, de clase media, de homo-marica-gay" (161).

Esta necesidad de auto identificación es muy similar a la que se representa en el cuento "Una mujer frente a un río”, de Eliécer Cárdenas Espinoza ${ }^{1}$, en cuyo discurso narrativo, la protagonista Laura, cuando entabla amistad con una mujer nativa de España que comparte la admiración por la figura de Antonio Machado y su poesía, a quien conoce en la ciudad de Soria, "en el parador que había sido morada del poeta", estima necesario hacer conocer su identidad personal de emigrante y en sus propias palabras se autodefine como una "sudamericana, ahora sin trabajo, desdichada en el amor y admiradora de Machado” (2014: 61).

En esta misma direccionalidad de pensamiento, la necesidad de remarcar o recuperar la identidad personal de los emigrantes se patentiza, también, en el cuento "Cara de bovino deprimido", de Adrián Carrasco Vintimilla², en el cual el protagonista siente la sensación de haber perdido los referentes identitarios, a consecuencia del viaje y de haber llegado a un país totalmente

1 (Cañar, 1950). Cuentista, novelista, dramaturgo y periodista. Sus publicaciones en cuento son las siguientes: Hoy al General (1971), El ejercicio (1976), Narraciones -con Jorge Dávila Vásquez- (1979), Siempre se mira al cielo (1986), La incompleta hermosura (1996), La ranita que le cantaba a la luna (1998), Relatos del día libre (2004) y El jabalí en el bar: historias de viajeros y emigrantes (2014).

2 (Cuenca, 1941). Economista, catedrático universitario, investigador social, ensayista y narrador. En cuento solo ha editado dos libros: Cara de bovino deprimido (2011) y Los morlacos (2011). 
desconocido, sentimiento que está muy presente entre los ecuatorianos en el extranjero, conforme le acontece a Manuel Sarango, quien en primera persona manifiesta: "Esta misma noche, cuando conocí a Washo Lema en la discoteca Matiz, terminé por desubicarme del todo. El viaje se me desbarajustó: yo ya no era yo ahora. $\mathrm{Y}$, aunque siga siendo yo, parece que ya no tengo ni nombre" (Carrasco Vintimilla 2011: 50).

\subsection{El emigrante ecuatoriano, un buscador permanente}

En la representación y recreación literaria de la identidad personal presente en los cuentos analizados, a través de los protagonistas de las ficciones narrativas, se ponen de relieve algunas de las características de los emigrantes ecuatorianos. En primer lugar, sale a flote una de las características privativas del ser humano, que es el de ser un buscador permanente, en cuyo interminable proceso "ha tropezado con muros y abierto puertas para reconocer, desde esos umbrales descubiertos, el espacio de lo establecido y aquello que permanece a su espera. Porque siempre el hombre ha sabido estar en el límite que desafía cualquier orden de lo real" (Zemelman 1998: 8).

En el cuento "La voz de los migrantes", de Carolina Andrade Freire ${ }^{3}$, luego del retorno al pueblo de origen (Hermosita), Rosario Vera Ortiz, la protagonista del viaje emigratorio hacia Estados Unidos, en respuesta a las interrogantes del médico rural del pueblo sobre por qué había regresado, al tiempo que trata de responder al interlocutor reflexiona sobre el sinsentido de la búsqueda que emprendió cuando, movida por la desilusión del lugar de origen, abandonó el Ecuador. En palabras de esta narradora protagonista: "Me fui buscando un mejor futuro, así decimos todos ¿verdad? Y, después de casi diez años, ya no entendía cuál futuro era el que buscaba" (Andrade Freire 2003: 68).

Este afán de búsqueda se evidencia, incluso, en el caso de los emigrantes solitarios, a quienes nadie espera en el desconocido lugar de llegada; sin embargo, si bien tienen la certeza de que nadie los va a recibir en la terminal aeroportuaria de arribo, siempre hay la tendencia a buscar, a mirar en todas las direcciones del lugar de llegada con la vana ilusión de encontrar a alguien que los reconozca, les dé importancia y les dote de sentido a la vida; pues, como dice el protagonista del cuento "Cómo se llamaba ese país", de Lucrecia Maldonado Rodríguez $z^{4}$, en frases de muy intensa emotividad: "de repente uno sabe que nadie nos espera en ninguna parte y sin embargo, sigue buscando con los ojos alelados aleteantes de sombras viejas la cara conocida que tal vez nos identificó entre la multitud" (Maldonado 2004: 77).

En el cuento "Cara de bovino deprimido", de Adrián Carrasco Vintimilla, en la búsqueda que emprende Manuel Sarango de la identidad del polémico ex árbitro de fútbol ecuatoriano Byron Moreno, llega al cuestionamiento de su propia identidad personal. En palabras de este ecuatoriano en Europa: "Pero sé que traje a Milán toda aquella sensación de incertidumbre, ¿quién es él? Y llegué acosado por el monstruo de ¿quién soy yo? [...]. Soy ecuatoriano sin duda alguna. Pero

3 (Guayaquil, 1963). Narradora, periodista y catedrática universitaria. En cuento ha publicado: Detrás de sí (1994), De luto (1998) y Revista y revuelta (2003).

4 (Quito, 1962). Cuentista, novelista, poeta, ensayista, periodista y catedrática universitaria. Entre sus publicaciones en narrativa breve destacan: No es el amor quien muere (1994), Mi sombra te ha de hacer falta (1998), Todos los armarios (2002), Como el silencio (2004) y Bip-bip (2008). 
precisamente ahí estaba la duda, ¿acaso todo esto te concierne a ti, Manuel Sarango?” (Carrasco Vintimilla 2011: 33). Las dudas sobre la identidad personal que inquietan a Manuel se hacen evidentes para quienes integran su entorno más inmediato, conforme lo advierte con toda claridad su pareja sentimental, la italiana Giulietta, quien manifiesta que cuando fueron a Milán a visitar a la madre de ella, el emigrante ecuatoriano "ya andaba con eso de buscar a sus paisanos, atormentándose con esas falsedades de ¿Quién soy? ¿Qué somos?” (50).

En respuesta a la necesidad de superar esta sensación de vacío, de extrema soledad y de no ser nadie en el país de destino emigratorio, se emprende la búsqueda de un ancla, aunque solo sea simbólica en el país de origen y entre quienes se quedaron en él. En esta direccionalidad, para sentirse alguien, para escuchar voces conocidas, para creer que hay personas que se interesan por lo que le acontezca en su vida, se busca la manera de comunicarse con los familiares que permanecen en el Ecuador y porque, además, a la comunicación se la considera como una condición indispensable, aunque no suficiente, para la constitución de la identidad personal (cf. Donoso 1998: 159).

Una experiencia de esta naturaleza es la que se representa en el relato "La decisión", de Gladys Rodas Godoy ${ }^{5}$, en el cual la protagonista, cuando llega a la ciudad de Madrid y es acogida en el hacinado piso compartido de una compatriota suya, lo primero que hace es tratar de comunicarse con los familiares que quedaron en el Ecuador a la espera de los recursos económicos que les permitan sobrevivir: "pidió a su amiga la llevara a donde podría hacer una llamada, era lo primero que necesitaba hacer antes de empezar su nueva vida. Tenía que escuchar la voz de sus hijos, saber que estaban bien, que podrían seguir sin ella, necesitaba tomar fuerzas para no derrumbarse" (Rodas Godoy 2014: 15).

\subsection{Los amores fugaces, como una característica de la modernidad líquida}

Cuando ya se encuentran en los países del hemisferio norte, algunos emigrantes se sienten influenciados por ciertos comportamientos culturales propios de la denominada modernidad líquida. Desde esta perspectiva y para explicar las características de las relaciones sociales y de pareja de la época actual se hace necesario retomar los planteamientos formulados por el sociólogo y filósofo polaco Zygmunt Bauman, quien propone la pertinencia de diferenciar entre la "modernidad sólida", a la que corresponde también una identidad sólida, frente a la muy reciente "modernidad líquida", en la que los individuos adoptan identidades líquidas, fluidas, que cambian rápidamente, que son inestables, negociables, transitorias, revocables.

En tiempos de modernidad líquida, las relaciones humanas se caracterizan por su transitoriedad, por su fugacidad: "nuestra sociedad 'ha hecho que las amistades, las aventuras amorosas y los matrimonios profundos y duraderos sean cada vez más difíciles de encontrar" (Bauman 2003: 65). En esta dirección de pensamiento, Adrián Carrasco Vintimilla sostiene que los amores líquidos son "las relaciones de bolsillo, que se pueden utilizar en caso de necesidad, pero que también pueden volver a confinarse en las profundidades del bolso cuando ya estorban”. Por ello, "las actuales 'parejas abiertas' abominan del compromiso, en particular el compromiso a largo

5 (Loja, 1957). Poeta, narradora, periodista y emigrante económica con rumbo a la nación ibérica. Tiene a su haber un solo libro de cuentos: La casa ajena (relatos) (2014). 
plazo, lo toman como una trampa que debe evitarse a toda costa" (Carrasco 2011: 68). Desde esta perspectiva, el desplazamiento físico de las personas de un país a otro los ubica en una situación ideal para el establecimiento de amores líquidos, en tanto se desenvuelven dentro de esa oposición borrosa entre el aquí del presente y el allá del pasado.

Sobre los amores líquidos Giuletta, una de las narradoras en segunda persona del cuento "Cara de bovino deprimido", de Adrián Carrasco Vintimilla, al contar la historia de su relación de pareja con el emigrante ecuatoriano Manuel Sarango recuerda que este aludía, en más de una ocasión, a que el vínculo sentimental que ellos mantenían es el típico de un amor líquido propio de la época contemporánea; motivo por el cual, desde que llegan a la ciudad de Messina, "la verdad sea dicha, le escucho ese cuento insoportable de que la nuestra es una relación desechable. Ahora afirma que no le queda duda, que el nuestro era un amor descartable, que podríamos desecharlo de en medio en cualquier momento, sin complicaciones" (2011: 19-20). Esta misma narradora, frente a la frialdad e indiferencia de Manuel, más adelante, habla de que pensaba en una traición para tratar de reanimar el amor de pareja que, de manera paulatina, se diluía e iba camino a la definitiva extinción. En palabras de la doctora italiana: "a veces tenía la peregrina idea de que quizá el adulterio nos haría bien a ambos o, por lo menos, nos abriría una salida. Hay parejas a las que la traición les anima, les hace soportar el deterioro y el desgano" (49). Y como lo expresa el propio Manuel, al final de la narración, mientras lleva a Giuletta a la cama: "ella viene contenta, ella sabe que es la del estribo" (55). Es decir, la última relación, para despedirse sin sentimentalismos y no volverse a ver nunca jamás.

En el cuento "De aquellos lares, de aquestos cielos", de Raúl Pérez Torres', de similar forma, la supuesta relación amorosa entre el emigrante ecuatoriano Martín y la escritora francesa Simone de Beauvoir, está condenada al fracaso. En este relato, es el ecuatoriano quien asume la condición de los amores líquidos característicos de la modernidad y, en esa perspectiva, el poder de decidir cuándo se da por concluida la relación sentimental de pareja, tanto en París como en Quito; para ello, "a partir de entonces, y sin poder satisfacer ninguna expectativa, esgrimió el arma de la prepotencia, mientras Simone se dejaba estar con una serena sofisticación que hacían más deleznables los sentimientos del estudiante" (2004: 65).

Cuando deciden radicarse en el Ecuador y las relaciones de pareja se vuelven a enfriar, de nada vale que Simone de Beauvoir reconozca y valore que el amor a la ciencia y otras cosas positivas en su vida, las aprendió del emigrante ecuatoriano: "de ti, tú me has enseñado todo, yo solamente estoy tratando de tomar la posta [...], no creo que lo haga tan mal, me acaban de dar otro contrato y debo prepararme. Si tú quisieras..." (69). Y como Martín le contesta "yo no quiero nada. Quiero dormir. Apaga la luz", Simone comprendió, "entonces que lo que buscaba ese Inca moderno era lavarse viejos rencores, viejas humillaciones, tan viejas como la historia de esta parte del mundo y le entró al juego hasta llegar a parecerse, hasta llegar a olvidarse de los Campos Elíseos y del Boulevard de Clichy y suplantarlos por la cordillera andina o las lagunas de Ozogoche" (70). Pero a la final nada tiene importancia, porque Martín no está para reconciliaciones que permitan cultivar un amor duradero y hasta el último momento le insiste a su pareja que se lleve todo, porque para

6 (Quito, 1941). Cuentista, novelista, poeta, dramaturgo, ensayista y gestor cultural. En narrativa breve ha publicado: Da llevando (1970), Manual para mover las fichas (1973), Micaela y otros cuentos (1976), Musiquero joven, musiquero viejo (1977), Ana la pelota humana (1978), En la noche y en la niebla (1980), Un saco de alacranes (1989), Cuando me gustaba el fútbol (1990), Solo cenizas hallarás (1995) y Los últimos hijos del bolero (1997). 
él nada relativo a ella o que le traiga sus recuerdos amerita preservarse; por ese motivo, pese a su profunda inclinación por la cultura letrada, sus palabras de despedida final son: "llévate los libros", con lo cual le pone punto final a una relación que estaba destinada a ser líquida, efímera, pasajera, momentánea.

\section{Crisis de identidad personal del sujeto emigrante}

Según el filósofo canadiense Charles Taylor, la crisis de identidad se refiere a una "forma aguda de desorientación que la gente suele expresar en términos de no saber quiénes son, pero también se puede percibir como una desconcertante incertidumbre respecto del lugar en que se encuentran" (Taylor 1996: 43). Para el sociólogo ecuatoriano Manuel Espinosa Apolo, la crisis de identidad se refiere al "extraviamiento, ausencia o confusión de la conciencia [de sí mismo] o del grupo [...]. La ausencia de esta conciencia o la pérdida del yo, como en los casos clínicos de alienación, anonimia, incomunicación, etc., es denominado como 'crisis de identidad"' (Espinosa 1995: 34).

En el marco de la crisis de identidad personal es necesario poner de manifiesto que entre los emigrantes que recién llegan al país de destino se producen situaciones bastante contradictorias y críticas, las cuales "pueden provenir del conflicto entre el deseo de confundirse con los otros para no sentirse marginado ni 'distinto', y el deseo de diferenciarse para seguir sintiéndose 'él mismo', conflicto que puede originar momentos confusionales por la mezcla entre los dos deseos, dos tipos de sentimientos, dos culturas, o momentos de despersonalización o desrealización" (Grinberg 1996: 89).

Las complejas circunstancias por las que atraviesan los emigrantes ecuatorianos desencadenan severas crisis de identidad, momentos en los cuales las personas que las padecen llegan a dudar hasta de su propia existencia, de quiénes han sido en el pasado, quiénes son en el presente o quiénes podrán llega a ser en el futuro, conforme lo testimonia la emigrante ecuatoriana Paulina León Crespo, quien se pregunta si la nueva existencia "es realmente solo un paréntesis de mi existencia, o sea una nueva existencia. O es el quiebre: ¿el paso de una antigua existencia a otra nueva? ¿Soy capaz de tener varias existencias: paralelas, perpendiculares, enmarañadas, espiraladas?” (León Crespo 2014: 282).

Como consecuencia de esta crisis de identidad personal y de no lograr integrarse en el lugar de residencia, el sujeto emigrante cae en la compleja ambivalencia de no saber a dónde pertenece, se mantiene como en el limbo, sin tener un lugar fijo en el que anclarse: "soy de allá, pero soy de aquí [...]. Soy de ambas partes [...]. Aparecen las figuras impostoras del vende patria, del camiseteado, del ridículo, de la Malinche, del traidor a la patria, del agringado, del españolizado, del metidoagente, del gringo de cuarta, del disque español, del disidente, del sospechoso, del tirado a gringo, del vendido" (Ampuero 2014: 37-38). Por ello, como dice esta autora, en relación a su propia identidad personal de emigrante, "ni ecuatoriana ni española. Me ubico en un tercer espacio fronterizo, lejos del logocentrismo. La rigidez de los conceptos patrios: identidad, pureza, pertenencia es una camisa de fuerza innecesaria para quien, como yo, ha optado por vivir en el margen, en la fractura, en la frontera, in between" (38).

Como en la película Ni de aquí, ni de allá, los protagonistas del desplazamiento físico originado en el Ecuador se ubican en una compleja situación límbica al no considerarse ya parte del país de 
origen pero sin sentirse tampoco integrados en el Estado nacional de destino, tal como lo testimonia una emigrante ecuatoriana: "Nosotros inmigrados somos un poco así, extranjeros en Italia y extranjeros en nuestra casa. Porque, cuando uno vuelve, no encuentra más las cosas que pensaba. Yo en mi país no conozco a casi nadie, todos salieron fuera, a Europa. Las otras amigas son casadas. Sí, está la familia y nadie más" (Pagnotta 2014: 78). Esta ambigua situación de los emigrantes ecuatorianos la ratifica otra entrevistada, quien expresa: "porque has aprendido a ser un poco italiana. Pues, estás aquí pero extrañas allá; vas allá, y extrañas acá [...] te sale también una crisis, de decir: ‘¿Dónde carajo me encuentro?’” (79).

La crisis de identidad personal que afecta a los emigrantes ecuatorianos ha sido ampliamente representada y recreada en las obras de narrativa breve seleccionadas como objeto de estudio. En el cuento "Johnnie the man", de Edwin Ulloa Arellano7, Juanito, primero, o, Johnnie, después, el personaje protagonista de la ficción narrativa, desde su estancia en el Ecuador adolece de una severa crisis de identidad personal, que parte de la orientación sexual, al convertirse en pareja sentimental de un famoso homosexual guayaquileño: "Estabas perdido... comerse un maricón no solamente trae mala suerte sino que es un estigma. El que monta no es cacorro, mascullas, estrujando el pelo para apretar las palabras que te arrojaron en cara: Juan es Meco... el marido de Ladrón de Levita" (Ulloa 1991: 166). En esta historia, la crisis de identidad persigue al protagonista hasta el país de destino emigratorio y se mantiene muy presente cuando retorna a Guayaquil con el ánimo de quedarse de manera definitiva, ya que por más esfuerzos que haya hecho para cambiar la vestimenta y apariencia externa, mientras camina en compañía de su familia, por uno de los centros comerciales de la ciudad origen, se siente observado e identificado: "No lo han olvidado, este mundo ha dejado de ser tuyo, no te pertenece y, aún cuando han pasado tantos años, sigues siendo un delincuente juvenil, cachero de maricones. Reclamas a Bubba... eres un niño pendejo que esconde sus mentiras bajo las faldas de su madre" (169). El protagonista del relato, como consecuencia de no haber podido superar el estigma social en la urbe de nacimiento, abandona el acariciado sueño de convertirse en propietario de un negocio y casarse con una mujer honesta, ya que a la final no pasa de ser el mismo Johnnie the man, no obstante haber pretendido modificar su identidad personal, luego del viaje emigratorio a Estados Unidos, país al que decide reemigrar: "te ríes, eres un hijueputa Johnnie y lo admites mientras preparas los papeles para regresar nuevamente a Los Ángeles en busca de tu identidad y núcleo” (170).

En el cuento "La voz de los migrantes", de Carolina Andrade Freire, la protagonista principal de la ficción narrativa: Rosario Vera Ortiz, pone en clara evidencia la crisis de identidad personal que la afecta, en virtud de que por su condición de emigrante su ser se escinde entre dos lugares: el de partida y el de llegada. Un allá y ayer, en donde está la mente y el espíritu y un aquí y ahora, en donde solo está la materialidad del cuerpo, produciéndose una problemática doble ausencia. Esta compleja circunstancia vital de la protagonista del relato se pone de manifiesto en la conversación que mantiene con el médico rural de Hermosita, el Dr. Rafael Jiménez, a quien le manifiesta:

Los que nos vamos dejamos espacios vacíos que son estúpidamente respetados por los que se quedan, ¿has notado eso en este pueblo?, y, cuando llegamos a otro lado, los del otro país ni viéndonos

7 (Riobamba, 1947). Cuentista, periodista, psicólogo y catedrático universitario. Tiene a su haber tres libros de cuentos: Yo tenía un vecindario de película mexicana (1981), Sobre una tumba una rumba (1992) y Cuentos (2009). 
quieren aceptar que estamos allá. Una puede estar en un lado y puede estar en ninguna parte. Por ejemplo tú, doctor. Estás aquí pero no estás aquí. Tu corazón ya se fue a Canadá y ojalá todavía esté allá para cuando llegues y lo nombres en francés. Tampoco estás ni estarás en tu citi, ¿dónde coño estás? Tus libros no son un lugar. Yo me fui hasta Estados Unidos, y nada. Recién llego a Hermosita antes no estuve, ahora sí porque ya sé quién soy. Hay que saber quién se es, o por lo menos quién no se es, para ocupar un lugar, y ese lugar tiene que ser diferente porque tú estás ahí, ¿tú entiendes? (Andrade Freire 2003: 72-73).

En los cuentos ecuatorianos analizados se advierte que hay casos extremos de crisis de identidad personal y de hiperbólica percepción de la misma, en los que por las condiciones infrahumanas en las que han caído los emigrantes ecuatorianos, en un proceso de desdoblamiento psíquico, se sueña con otra identidad, de la que los separa un abismo de distancia, conforme le acontece al narrador protagonista del relato "Premoniciones del exilio", de Patricio Viteri Paredes ${ }^{8}$, un ecuatoriano mendigo y alcohólico en las calles de la ciudad de Madrid, que se imagina ser un ejecutivo de ventas y tener una esposa y una enternecedora hija y para cerciorase que no constituye una mera ilusión lo verbaliza, aunque solo sea para sí mismo: "Soy un hombre, tengo treinta y cinco años, me llamo Patricio, mi esposa se llama Consuelo y mi hija Elisa, vivo en Madrid desde hace ocho años en Isidra Jiménez No 5 y provengo de un país latinoamericano por donde pasa una línea que no existe" (Viteri Paredes 2004: 101).

A pesar de los ensueños de este personaje, hay momentos en los que se despierta del delirio alcohólico, se enfrenta a la dura realidad del presente y él mismo se observa y describe externamente como el mendigo harapiento, maloliente, sin techo ni familia, en que ha llegado a convertirse, luego de un lento proceso de movilidad social descendente y de degradación moral y física:

Llevo unas botas muy grandes y enlodadas que alguna vez fueron marrones; el borde exterior de la bota derecha está descosido y de allí brota, como una lengua mugrienta, un trozo de calcetín negro. Visto unos vaqueros demasiado anchos y empapados desde las deshilachadas bastas a las rodillas; hay manchas de comida en los muslos y en las ingles. Traigo un abrigo azul que me cubre hasta el culo y tiene parches en las axilas, en un codo y en los puños; también llevo jerséis y una camiseta por dentro (tampoco huelo tan bien que digamos) (Viteri Paredes 2004: 102-103).

La cruda realidad del protagonista, que deviene luego de auto percibirse como el mendigo en que se ha convertido, es ratificada por un amigo español de similar condición, quien le enrostra: “¡Me cago en tus muertos ecuatoriano! [...] ¡No me digas que te golpearon por creer que cualquier tía con una niña eran tu esposa y tu hija! Lo que me extraña es que no te hayan matado todavía. Ya me han contado que duermes en casas abandonadas, que hablas de libros y te crees un señorito. ¡Ja, ja, ja!” (Viteri Paredes 2004: 103).

Cuando el proceso emigratorio ha golpeado al sujeto y lo ha puesto en situaciones límites de mendicidad e indigencia, la crisis de identidad personal es tan pronunciada que, incluso, se llega a dudar de quién es uno, de dónde proviene y hacia dónde se dirige; conforme lo pone en evidencia el narrador omnisciente de "Cómo se llamaba ese país", de Lucrecia Maldonado

8 (Quito, 1955). Cuentista, ensayista, periodista, editor y crítico literario. En cuento ha publicado: Subterráneos (1987), No merecemos esas calles (2003) y Advertencia del desterrado (2010). 
Rodríguez, el cual expresa: "De repente la sensación de [...] volver a la cuna caliente de volver al hueco profundo y oscuro del abrazo mayor y de no acordarse ni saber de qué color eran los ojos de la madre ni quién mismo es uno ni cómo se llamaba ese país" (Maldonado Rodríguez 2004: 79).

\section{Las identidades múltiples, otra expresión de crisis entre los emigrantes}

Hay que tener presente, también, que las incertidumbres y zozobras propias de una época de cambios o, más bien un momento histórico de cambio de época, como es la contemporánea, repercute, con inusitada fuerza, en los procesos de construcción y reconstrucción de la identidad, que caracterizan a los sujetos posmodernos y, de manera especial, a los emigrantes económicos provenientes del hemisferio sur, en razón de que ya no hay ni referencias estables ni las pertenencias definidas que otrora servían para fijar horizontes y contenidos en la configuración identitaria de un nosotros y de un yo (cf. Gómez 2000: 11). En estas nuevas y complejas circunstancias emergen preguntas que hay que tratar de responder en medio de incertidumbres crecientes, en un mundo en el que todo cambia muy de prisa y para hacerlo son necesarios los sentidos de pertenencia, los referentes identitarios, los marcos de orientación, los valores compartidos, el sentido de lo que somos y hacemos en el presente y en el futuro (12).

De manera adicional, hay que tener en cuenta que, a consecuencia de la complejidad del entorno familiar, comunitario y social amplio en el que se desenvuelven los seres humanos, en sentido general y los emigrantes, en particular, advienen las identidades múltiples que los define y caracteriza, por cuanto "todo individuo se maneja simultáneamente en varios círculos, desde el individual y familiar, hasta el más amplio de pertenencia a una comunidad, región, nación o país, pasando por el del grupo político, étnico sindical o profesional en el que se desenvuelve" (Aínsa 2012: 112-113).

En el caso específico de los emigrantes, una expresión de las identidades múltiples que los caracterizan a muchos de ellos constituye la doble nacionalidad que adquieren algunos, circunstancia que complica aún más la identidad personal de quienes toman esta decisión. Las repercusiones se hacen sentir, en todas sus formas de expresión de las personas, como individuos o como parte de un grupo social mayor:

...así puede explicarse el cada vez más importante fenómeno de la doble nacionalidad, al que irónicamente podríamos llamar "bigamia" de patrias, bipatrismo que caracteriza la situación de buena parte de los exiliados e inmigrantes. Tener doble pasaporte no es simplemente una comodidad para cruzar fronteras, sino un documento que traduce una situación de hecho en que parte de una identidad ha cedido su espacio a un territorio de adopción (Aínsa 2012: 115).

Claro ejemplo de una persona, en concreto, que se autopercibe como portadora de identidades múltiples es Amin Maalouf, quien ante la pregunta de qué se siente más, si francés o libanés, siempre responde lo mismo: “¡las dos cosas!”, porque "lo que hace que yo sea yo, y no otro, es ese tratar en las lindes de dos países, de dos o tres idiomas, de varias tradiciones culturales. Es eso justamente lo que define mi identidad" (cf. Nebreda 2000: 152). 
En los cuentos ecuatorianos analizados un ejemplo de identidad múltiple, presente en un mismo sujeto, es el que se pone de manifiesto en el relato "Cara de bovino deprimido", de Adrián Carrasco Vintimilla, en cuya historia ficticia Aron Bello, uno de los personajes protagónicos de la historia se autodefine como "ecuatoriano y a mucho orgullo, pero también soy un catalán de pies a cabeza" (2011:25). Al final del mismo relato, Manuel Sarango alude a las varias identidades que se le atribuyen al controvertido exárbitro ecuatoriano de fútbol Byron Moreno, quien pasó de ser el árbitro ladrón que robó un partido a Italia en el Campeonato Mundial de Fútbol del año 2002, cuyo nombre en sentido irónico se le dio a cuatro urinarios públicos de una plaza, hasta ir desdibujando esa memoria de personaje maldito y ser reconocido con el nombre de la plaza entera y con ello comenzó a escribirse otra historia; pues como dice uno de los narradores testigos de la historia: "Byron Moreno encontró diversas formas de estar en la plaza. Quizás a todos los que venimos de allá nos sucede igual mudanza: a tira y jala con los cambios encontramos alguna forma de vivir en estas tierras" (55). En razón de las anteriores reflexiones se puede ratificar que la identidad personal de los sujetos emigrantes ecuatorianos es algo mudable, cambiante, flexible, temporal. Nunca algo inamovible y fijo, de una vez y para siempre.

\section{Los cambios que genera el proceso emigratorio en sus protagonistas}

Entre los emigrantes ecuatorianos en Madrid, todos los cambios en la imagen que tienen de sí mismos "cobran sentido y continuidad a partir de la coherencia que les da el estar inmersos en un proyecto de lucha por el control del destino" (Thayer 2007: 106). Ya en el Estado nacional de destino, el cambio más significativo que tienen que afrontar los emigrantes ecuatorianos es el de asumir una vida más individualizada, propia de la sociedad de acogida, tal como manifiesta el investigador citado: "llegar a un contexto extraño donde los lazos afectivos son menores y más débiles que los que han dejado atrás, lleva a los inmigrantes a sumergirse en una sensación de vacío afectivo que conduce, en el mediano plazo, a un quiebre emocional con su pasado y con el contexto donde este se desarrolló" (Thayer 2009: 246-252).

El abandono del Ecuador, el alejamiento del entorno social más próximo y de las personas que frecuentaba y con las que se interrelacionaba a diario genera, en el emigrante, una serie de cambios bruscos. En el Estado nacional de destino, como dice María Fernanda Ampuero, la movilidad social descendente es evidente e inmediata: "pasas de ser hijo a ser huérfano, sereno a desconcertado, capaz a desvalido, ciudadano a paria ('sin papeles', 'ilegal'), nombre propio a estadística, profesional cualificado a mano de obra barata, conocido a extraño, propietario de la tierra a arrendatario sospechoso" (Ampuero 2014: 30).

En el ámbito de los cuentos ecuatorianos seleccionados como objeto de análisis, en relación a los cambios que genera el proceso emigratorio en sus protagonistas, se pueden describir y analizar algunos ejemplos, comenzando por aquellos en los que se produce el cambio del nombre de pila que les habían puesto los padres en el país de origen y adoptar uno que les parece más conveniente en el destino emigratorio, porque les facilita la posibilidad de integración; pues, como dice la protagonista de uno de los relatos testimoniales de Galo Galarza Dávila?: "Yo misma no me

9 (Guaranda, 1956). Narrador, ensayista y diplomático. En el ámbito de la cuentística tiene tres libros: En la misma caja (1980), La dama es una trampa (1996) y El turno de Anacle (2002). 
llamo Carmen Sanders, como usted cree y me llama, no, yo en verdad me llamaba en el Ecuador Lucinda Garzón. Pero me cansé de llamarme así, me parecía el mío un apellido demasiado sonoro, gutural, odioso, y un buen día dije: me lo cambiaré, qué caray y me lo cambié y no pasó nada” (2009 [1996]: 190).

En el cuento "Aeropuerto", de Jorge Velasco Mackenzie ${ }^{10}$, los cambios se ponen de manifiesto en la vestimenta, en lo externo, en el cuerpo y en el espíritu de los protagonistas de la emigración referidos en esta narración. En el caso de Alejandra Sánchez, la protagonista principal del relato, por insinuación de su amiga que le dio albergue en Estados Unidos, cambia su presentación externa, a fin de adecuarse a la cultura, costumbres, modales y forma de vida que llevan en la ciudad de Nueva York. En palabras del narrador omnisciente del relato:

...ella fue quien le enseñó a vivir, le dio esos consejos sabios, pide más, le decía, engorda y Alejandra que era huesos, empezó a tomar emulsiones, a subirse la falda, a beber whisky sin cara de náusea, los hombres deben de ser ricos repetía, nada de engrupimientos, porque el amor no entraba en sus planes, Eugenia era la amiga sabia, la calmosa ninfa del diván que miraba a los hombres con aires de artista sueca (Velasco Mackenzie 2004 [1974]: 321-322).

En "Johnnie the man", de Edwin Ulloa Arellano, Johnnie en Estados Unidos o Juanito en Ecuador, cuida su vestimenta y apariencia externa, a fin de que, entre los familiares, amigos y conocidos, se noten los cambios que ha experimentado a raíz de su viaje emigratorio y de esta manera prepara un ambiente más propicio para reinsertarse, en mejores condiciones, cuando retorne a radicarse, de manera definitiva, en la ciudad de Guayaquil: "tenías que venir elegante, eso es cierto [...], los tuyos incansables y admirados por las camisas y el corte de pelo; eres un sueño Johnnie" (Ulloa Arellano 1991: 165-166).

Martín, el protagonista del relato "De aquellos lares, de aquestos cielos”, de Raúl Pérez Torres, luego de arribar a Francia y establecer una relación amorosa con Simone de Beauvoir, explicita inmediatos y radicales cambios en los pensamientos, en la visión del mundo, en la vestimenta y en la presencia física, que lo alejaban de las convicciones y expectativas que tenía en su país de origen antes de salir y le abrían las puertas del primer mundo en donde ahora residía: "vislumbró ídolos caídos de su pueblo, esperanzas falseadas, utopías rotas, y se sintió confundido, estafador, estafado. Tiró entonces sus pantalones de un casimir marchito y se enfundó en los jeans que lo igualaban a todos los jóvenes del mundo" (Pérez Torres 2004 [1989]: 65).

En el cuento "El detective gilipollas", de Carlos Carrión Figueroa ${ }^{11}$, quienes advierten los cambios en el emigrante retornado son los vecinos del pequeño pueblo, en donde compró una propiedad, construyó una casa y se radicó de manera definitiva. Estas percepciones sobre el protagonista del relato las patentizaron los paisanos cuando fueron interrogados por el teniente político de la

10 (Guayaquil, 1949). Novelista, cuentista, poeta, dramaturgo y catedrático universitario. En narrativa breve tiene varios libros publicados: De vuelta al paraíso (1975), Como gato en tempestad (1977), Raymundo y la creación del mundo (1979), Músicos y amaneceres (1986), Palabra de maromero (1986), Clown y otros cuentos (1988) y Desde una oscura vigilia (1992).

11 (Malacatos, Loja, 1944). Cuentista, novelista, poeta, ensayista, columnista de opinión, crítico literario y catedrático universitario. En narrativa breve ha publicados: Porque me da la gana (1969), Ella sigue moviendo las caderas (1979), Los potros desnudos (1979), El más hermoso animal nocturno (1982), El corazón es un animal en celo (1995), Doce cuentos de amor y una ballena (2004) y Habló el rey y dijo muuu (2011). 
parroquia, que dirigió la investigación judicial para esclarecer los verdaderos móviles y circunstancias en que se produjo la misteriosa muerte del protagonista, ocasión en la que "le decían que era un hombre solitario y sombrío, como si tuviera un pesar oculto o lo socavara el pesar de una mujer ingrata [...]. Otros que los años de emigrante lo habían envejecido por dentro. No era él desde que había vuelto. Ni el pueblo su pueblo" (Carrión Figueroa 2011: 62).

En cuanto a los cambios en la escala de valores, existen emigrantes que están muy conscientes de la degradación moral que ha afectado a su identidad personal, como consecuencia de la emigración o al menos de los cambios radicales que se han producido en ellos, conforme lo demuestra el narrador protagonista del cuento "Ya no tengo que llorar", de Carlos Carrión Figueroa, quien de manera permanente está renegando de los nuevos y negativos rasgos de identidad personal que se han generado en él y en su esposa Maribel, a consecuencia de la emigración desde la ciudad de Loja hacia la capital de España. En esta historia ficticia lo más grave es que de las trágicas repercusiones del viaje emigratorio, el narrador protagonista no avizora ninguna posibilidad de mejora ni salida: "Esta mierda es lo que ha hecho la maldita migración con Maribel y conmigo. Nos ha sacado de nuestro país, de nuestra vida, de nuestro corazón. Ya no somos los mismos nunca más: mi única esperanza de trabajo, de futuro, de alegría, solo es la esperanza de matar a Maribel. Es decir de matarme a mí mismo, Dios mío” (Carrión Figueroa 2005: 22-23).

\section{La metamorfosis de los emigrantes ecuatorianos}

Según el Diccionario de la lengua española, la metamorfosis hace referencia a la "transformación de algo en otra cosa" o a la "mudanza que hace alguien o algo de un estado a otro, como de la avaricia a la liberalidad o de la pobreza a la riqueza" (Real Academia Española 2014). Este complejo proceso de transformación identitaria obedece a que el que se va, el exiliado, el emigrante, se abre a un mundo de incertidumbres, de moradas provisionales. En el itinerario, el emigrante sufre vejaciones y violaciones que le transforman hasta el alma; pues como expresa Adrián Carrasco Vintimilla: "En la percepción del país de destino, el inmigrante es el estereotipo de un problema, la imagen de la pobreza y de la cultura ajena. En su nueva 'casa', el inmigrante sufre transformaciones emocionales, espirituales, incluso físicas" (Carrasco Vintimilla 2011: 60-61). Al regreso, si el acariciado sueño del postergado retorno se hace realidad, es un inadaptado, un desarraigado, casi un desconocido por las mudanzas que se han producido, tanto en el emigrante como en uno y otro lado de las fronteras.

Una de las expresiones de la metamorfosis del emigrante ecuatoriano, que se dirige con rumbo hacia Estados Unidos, se encuentra en el denominado "Choloboy" que se caracteriza por las pretensiones de "yanquización" o norteamericanización, "como resultado del impacto que provoca en los estratos juveniles citadinos, la cultura de masas transnacional. Esta norteamericanización se manifiesta en sus hábitos citadinos [...], y llega a altos niveles de alienación en algunos individuos que viven en condición de emigrados en las grandes ciudades de Estados Unidos" (Espinosa 1995: 58-59).

Un ejemplo de metamorfosis de las mujeres ecuatorianas que se dirigen a Estados Unidos es el que resume Linda Machuca. Según esta autora, la mujer emigrante en el país de origen era caracterizada como sumisa, esclava, fácil de dominar, buena para la cocina, sin cultura, poca o ninguna 
educación y de bajo perfil en la comunidad en la que se desenvuelve; sin embargo, luego de arribar al país de destino y de incorporarse a trabajar, experimenta transformaciones importantes como la independencia económica, que le permite tomar decisiones y actuar con criterio propio; mejora su autoestima y empieza a demostrar su potencial en la sociedad americana; diversifica el horizonte cultural al ponerse en contacto con personas provenientes de diferentes países del mundo; y ya no tiene problemas en ser infiel al percibir que en el nuevo ambiente muchas conductas reprochables en el Ecuador son permitidas. Toda la suma de cambios antes enunciados desembocan en una auténtica "transformación física de su persona, la cual viene acompañada de importantes cambios en su psicología y, lo más importante, también en sus aptitudes y capacidades" (Machuca 2005: 92).

En parecida línea de transformación identitaria, para una mujer lesbiana que tenía el deseo de convertirse en hombre, la llegada a otro país se ha convertido en la mejor oportunidad para que se produzca toda una metamorfosis, tanto en la externalidad de su cuerpo como en su psiquis. Según el testimonio que brinda, el viaje también "ha permitido expresarme con mayor intensidad para sacar a luz esos sentires ocultos y cruzar también fronteras corporales. Como por ejemplo el cortarme el pelo o el cambiar mi vestimenta [...]. Esta experiencia pone a flote un desbordamiento de mis masculinidades existentes, en mi ser lesbiana" (Aguirre 2014: 146). Sobre esta experiencia de transformación de la identidad personal es interesante el testimonio que externaliza la emigrante, quien cuando, por primera vez, en el país de destino, va a la peluquería para hacerse cortar el cabello y semejar el hombre que siempre había querido ser, para asombro del estilista que la atendió, la ecuatoriana le pidió que le rape el cabello, a fin de que la transformación sea más evidente e inmediata:

Al fin opté por decirle: ¡Péleme! El peluquero se asustó y me dijo: ¿Cómo? ¿Está segura? ‘SSí, péleme, le dije!' [...]. Fui descubriendo mi proceso trans y me permití vivirlo. Si la primera salida del clóset fue difícil esta segunda tampoco era tan fácil, incluso encontrándome lejos de mi país. Ahora se cruzaban otros factores: ya no era la 'rara', 'tortillera', ahora era rarx, trans y migrante (149).

En los cuentos seleccionados como corpus narrativo de análisis, el proceso de metamorfosis tiene varias maneras de ponerse de manifiesto. En el cuento "El regreso", de Francisco Tobar García ${ }^{12}$, el retorno de Anselmo, el protagonista de la historia, constituye un momento cráter de la narración, en el que se confrontan las distintas expectativas y visiones que tienen los familiares respecto del emigrante retornado que esperan en el aeropuerto de Quito. Por un lado están las inquietudes del padre y de la madre de Anselmo, quienes aspiran que el viaje no haya cambiado demasiado a su hijo: "-Dios que nuestro hijo sea el mismo [...]. - -Lo que temo es que desentone. Ellos son tan buenos muchachos... Yo sé que vienen del campo, pero no quisiera que mi hijo los mirara, bueno, por encima del hombro" (Tobar García 2005: 48). En razón de estas expectativas de los padres del emigrante retornado, sino fuera por las palabras de la abuela que también estaba presente, ni tan siquiera reconocen al hijo cuando sale desde el interior de la puerta de arribo:

12 (Quito, 1928-1997). Poeta, novelista, cuentista, dramaturgo, periodista y diplomático. Su único libro de cuentos publicado se titula Los quiteños (1981). 
Solo entonces se dieron cuenta los padres que el desconocido era Anselmito [...]. - ¡Qué dicha tan grande de verte!- decía la madre; empero no estaba del todo convencida. Ella misma esperaba otro hijo, no a este que salía como brotado de la nada. Su hijo debía ser otro, y ella no atinaba a describirlo. - Casi no te reconozco..." (Tobar García 2005: 50-52).

En cambio, entre los primos venidos desde una provincia de la Sierra norte del Ecuador, a pesar de la mala voluntad y prejuiciosa actitud hacia el emigrante que regresa a su lugar de origen, de similar forma a lo que les aconteció con los padres del protagonista, los radicales cambios en la apariencia física del protagonista los desconciertan:

Esperaban un cambio total, pero jamás un cambio que los despistara a ese extremo. ¡Anselmo era un gringo de verdad...! [...] ¡Imposible reconocerlo, si hasta había cambiado de color, ya no era el chagra de tez oscura, sino un hombre blanco, perfectamente blanco! A Pánfilo -el primo mayor- lo que le indignaba era el brillo extremado de los zapatos. ¡No hay derecho a usar zapatos!, dijo a sus primos" (50-52).

Esta visión crítica de los familiares, en contra del emigrante retornado de Estados Unidos, es compartida por Eufemia, una de las vecinas de la familia de Anselmo, quien murmura: "no les miento, parecía un actor de cine, me muero qué modales, qué iba a parecer hijo de ese chagra que es Roberto y la cholota de la mama" (51). El propio personaje protagonista tiene su propia autopercepción, aunque no considera que el viaje emigratorio le haya producido cambios tan radicales; por ello, le dice al papá: “- Vaya, papá, ni que no me hubieran visto un siglo. Claro que soy yo, caray, tanto no habré cambiado" (51). Y a la prima Elsa le confiesa que está desorientado: “- Mira, Elsa, yo sé que soy un hombre de campo, hijo de campesinos, aunque haya nacido en Quito. Yo amo a esta ciudad y también la odio. No la entiendo. Voy a volverme loco. No quería regresar, ¿sabes?” (57).

En el abigarrado proceso de la metamorfosis identitaria de los emigrantes ecuatorianos, tampoco faltan quienes tratan de ocultar hasta el color de su cabello y el de los ojos para poder borrar la identidad de origen y ser admitidos e insertados, con más facilidad, en la sociedad del país de recepción, tal como lo narra un personaje que se cambió el color de los ojos, con el propósito de borrar los rasgos que lo diferencian de los nativos, en una clara muestra de intertextualidad literaria que alude al poeta afrocubano Nicolás Guillén y desde un yo protagonista manifiesta: "qué me hubiera imaginado que con el paso de los años iba a tener el pelo rubio y los ojos azules (...). Y no avergüenza decirlo. Yo ya no soy acomplejado [...]. Y vea usted, mi señor, ya tengo lo que tenía que tener, como dice el poema del negrito Guillén” (Galarza 2009: 84-85).

Otra manera de poner en evidencia la metamorfosis de los emigrantes ecuatorianos es a través del cambio de identidad sexual; complejo proceso de transformación identitaria que se facilita porque Estados Unidos se percibe como la tierra de la libertad y de las oportunidades para realizar los cambios que no estaban permitidos en el Ecuador, según lo cuenta el narrador protagonista de otro de los relatos testimonio de Galo Galarza Dávila, quien con inversión de mucho dinero y a base de varias cirugías logra cambiarse de sexo y con ello llega a ser lo que siempre ha querido ser desde cuando vivía en Ecuador: "Mi nombre ahora es Julieta Galindo Macías. En el Ecuador era Julio Manuel Galindo Macías. Toda la vida me tuve que pasar con miedo, escondiendo mi 
verdadera pasión, mi inclinación natural por los hombres. Solo aquí en esta sociedad libre, y después de gastarme todos mis ahorros me lograron cambiar de sexo” (2009: 106).

En el cuento “Te escribiré desde París”, de Raúl Vallejo Corral ${ }^{13}$, Nathalie, una de las protagonistas del relato, narra la historia de un travesti ecuatoriano, quien completa su proceso de metamorfosis a través de una cirugía, aunque luego, cuando ya no hay ninguna posibilidad de vuelta atrás, se arrepienta hasta lo más profundo de su ser el haberlo hecho. En expresiones de esta futura emigrante en París: "Mi amiga se operó y ahora está arrepentida. Estaba pensando únicamente en un busto un poco más grande que estas tetitas que me brotan con las hormonas. Mira, la gente se vuelve loca conmigo por lo que soy. Si me convierto en mujer, pierdo mi encanto" (1992: 161).

Los ejemplos citados permiten demostrar que la acumulación de cambios cuantitativos que experimentan los emigrantes ecuatorianos en los países de destino deviene en cambios cualitativos que los transforman radicalmente, en una verdadera metamorfosis de naturaleza identitaria, hasta llegar a convertirlos en personas radicalmente diferentes de las que eran antes de emprender el viaje emigratorio desde el Ecuador.

\section{Conclusión}

Los principales rasgos de la identidad personal del protagonista que representa al emigrante ecuatoriano, de carácter internacional, han sido recreadas en varios de los cuentos analizados, en los cuales se lo representa como un sujeto signado por la ambivalencia, según las obras de narrativa breve de Adrián Carrasco Vintimilla y Eliécer Cárdenas Espinoza, que recrean literariamente la ruta emigratoria originada en Ecuador y con dirección hacia España. Al ecuatoriano en el extranjero se lo patentiza, también, como un buscador permanente de un nuevo horizonte de vida, de nuevos escenarios de progreso material y espiritual y de un futuro mejor, para sí mismos y para su respectiva familia que permanece en el país de partida o ha logrado reunificarse en el extranjero. Esta indesmayable actitud de búsqueda se pone de manifiesto en los cuentos de Adrián Carrasco Vintimilla, Gladys Rodas Godoy, Lucrecia Maldonado Rodríguez y Carolina Andrade Freire. Las relaciones sociales momentáneas propias de la denominada modernidad líquida y, como una evidencia de ellas, los amores de pareja, de naturaleza descartable, desechable y de fugaz duración se recrean en los protagonistas ficticios de los cuentos de autoría de Adrián Carrasco Vintimilla y Raúl Pérez Torres. La compleja crisis de identidad personal de los protagonistas ficcionales que representan a los emigrantes ecuatorianos se hace explícita en los cuentos de Edwin Ulloa Arellano, Patricio Viteri Paredes, Lucrecia Maldonado Rodríguez y Carolina Andrade Freire, en torno a la emigración con rumbo a Estados Unidos y España. En similar perspectiva, las identidades múltiples de algunos emigrantes ecuatorianos se patentizan en el cuento de Adrián Carrasco Vintimilla. Los cambios devenidos de la emigración en los protagonistas del desplazamiento físico de personas, que se han dirigido al norte del continente americano o el Viejo Mundo, se recrean en los cuentos de Raúl Pérez Torres, Carlos Carrión Figueroa, Edwin Ulloa Arellano, Jorge Velasco

13 (Manta, 1959). Novelista, cuentista, poeta, ensayista, antólogo y catedrático universitario. Entre los principales libros de cuentos de su autoría se pueden mencionar: Cuento a cuento cuento (1976), Daguerrotipo (1978), Máscaras para un concierto (1986), Solo de palabras (1988), Fiesta de solitarios (1992), Huellas de amor eterno (2000) y Pubis equinoccial (2013). 
Mackenzie y Galo Galarza Dávila. Y cuando las transformaciones son radicales se llega, incluso, hasta una verdadera metamorfosis identitaria, conforme se recrea en los personajes protagonistas de los cuentos de Francisco Tobar García, Galo Galarza Dávila y Raúl Vallejo Corral, en los cuales se ponen de manifiesto los cambios en el color de la piel, en el cabello, en los ojos y hasta en la identidad sexual y genérica de algunos protagonistas que recrean, narrativa y ficcionalmente, a los emigrantes ecuatorianos.

\section{Referencias bibliográficas}

Aguirre, A. (2014). Transgrediendo fronteras internas y externas. In D. Falconí Trávez (Ed.), "Me fui a volver": narrativa, autorías y lecturas teorizadas de las migraciones ecuatorianas (pp. 143-155). Quito: Universidad Andina Simón Bolívar, Sede Ecuador / Corporación Editora Nacional.

Aínsa, F. (2012). Palabras nómadas: Nueva cartografía de la pertenencia. Madrid-Frankfurt: IberoamericanaVervuert.

Ampuero, M. F. (2014). Vivir in between. In D. Falconí Trávez (Ed.), "Me fui a volver": narrativa, autorías y lecturas teorizadas de las migraciones ecuatorianas (pp. 29-41). Quito: Universidad Andina Simón Bolívar, Sede Ecuador / Corporación Editora Nacional.

Andrade Freire, C. (2003). La voz de los migrantes. In Revista y revuelta (pp. 63-76). Quito: Eskeletra.

Bauman, Z. (2003). De peregrino a turista, o una breve historia de la identidad. In S. Hall, P. du Gay (Eds.), \& H. Pons (Trad.), Cuestiones de identidad cultural (pp. 40-68). Buenos Aires: Amorrortu.

Cárdenas Espinoza, E. (2014). Una mujer frente a un río. In El jabalí en el bar: historias de viajeros y emigrantes (pp. 57-62). Cuenca: Imprenta Mercedes.

Carrasco Vintimilla, A. (2011). Cara de bovino deprimido. Prólogo de F. Aguilar. Cuenca: Universidad de Cuenca.

Carrión Figueroa, C. (2005). Ya no tengo que llorar. In VIII Bienal del cuento ecuatoriano Pablo Palacio (pp. 15-34). Quito: CEDIC.

- (2011). El detective gilipollas. In Habló el rey y dijo muuu (pp. 55-69). Quito: El Conejo.

Donoso Pareja, M. (1998). Ecuador: identidad o esquizofrenia (ensayo). Quito: Eskeletra.

Espinosa Apolo, M. (1995). Los mestizos ecuatorianos y las señas de identidad, $3^{\mathrm{a}}$ ed. Quito: Tramasocial.

Falconí Trávez, D. (Ed.) (2014). "Me fui a volver": narrativa, autorías y lecturas teorizadas de las migraciones ecuatorianas. Quito: Universidad Andina Simón Bolívar, Sede Ecuador / Corporación Editora Nacional.

Galarza Dávila, G. (2009 [1996]). La dama es una trampa, 2a ed. Quito: Eskeletra.

Gómez García, Pedro (Ed.) (2000). Las ilusiones de la identidad. Madrid: Cátedra.

Grinberg, L.; Grinberg, R. (1996). Migración y exilio. Estudio psicoanalítico. Madrid: Alianza.

León Crespo, P. (2014). Fragmentos de un diario de viaje. In D. Falconí Trávez (Ed.), "Me fui a volver": narrativa, autorías y lecturas teorizadas de las migraciones ecuatorianas (pp. 267-291). Quito: Universidad Andina Simón Bolívar, Sede Ecuador / Corporación Editora Nacional.

Machuca, L. (2005). Mujer inmigrante: metamorfosis en los Estados Unidos. In Programa Andino de Derechos Humanos (Ed.), Migración, desplazamiento forzado y refugio (pp. 87-94). Quito: Universidad Andina Simón Bolívar, Sede Ecuador.

Maldonado Rodríguez, L. (2004). Cómo se llamaba ese país. En Como el silencio (pp. 75-80). Quito: Eskeletra. 
Nebreda, J. J. (2000). El marco de la identidad, o las herencias de Parménides. En P. Gómez García, P. (Ed.), Las ilusiones de la identidad (pp. 151-180). Madrid: Cátedra.

Pagnotta, C. (2014). La migración ecuatoriana a España e Italia: historias, memorias e identidades 1995-2007. Quito: Corporación Editora Nacional / Universidad Andina Simón Bolívar, Sede Ecuador.

Pérez Torres, R. (2004 [1989]). De aquellos lares, de aquestos cielos. En Letras del Ecuador: Literaturas del exilio, 186 (pp. 63-71). Quito, Casa de la Cultura Ecuatoriana “Benjamín Carrión”.

Real Academia Española (2014). Diccionario de la lengua española, 23a ed. Madrid: Espasa Calpe.

Roca Sierra, M.; \& Sanz Villanueva, S. (Eds.) (2003). La construcción del sujeto en la narrativa española actual. Madrid: Fundación Universitaria Española.

Rodas Godoy, G. (2014). La casa ajena (relatos). Quito: s.e.

Salazar Estrada, Y. (2016). El sujeto emigrante en el cuento ecuatoriano 1972-2014. Tesis de doctorado. Universidad Complutense de Madrid.

Sanfeliu, I.; \& Varona, J. (Eds.) (2010). Migración, racismo y poder: el narcicismo de las pequeñas diferencias. Madrid: Biblioteca Nueva.

Taylor, C.; \& Lizón, A. (Trad.) (1996). Fuentes del yo: la construcción de la identidad moderna. Barcelona: Paidós.

Thayer Correa, L. E. (2007). Inmigrantes ecuatorianos en la comunidad de Madrid: la apropiación del espacio y la expropiación del tiempo. Madrid: Complutense.

- (2009). La expropiación del tiempo y la apropiación del espacio: la incorporación de los inmigrantes latinoamericanos a la comunidad de Madrid. Tesis de doctorado. Universidad Complutense de Madrid.

Tobar García, F. (2005 (1981]). El regreso. En Los quiteños, 2a ed. (pp. 46-62). Quito: La Palabra.

Ulloa Arellano, E. (1991). Johnnie the man. In Primera Bienal del Cuento ecuatoriano Pablo Palacio: obras premiadas (pp. 165-170). Quito: CEDIC.

Vallejo Corral, R. (1992). Te escribiré desde París. In Fiesta de solitarios (pp. 139-178). Quito: El Conejo.

Velasco Mackenzie, J. (2004 [1974]). Aeropuerto. En E. Viteri, E. (Ed.), Antología básica e historia del cuento ecuatoriano, $11^{\text {a }}$ ed. (pp. 320-323). Quito: Artes Gráficas Señal.

Viteri Paredes, P. (2004). Premoniciones del exilio. In Puro cuento: antología (pp. 95-104). Quito: Casa de la Cultura Ecuatoriana "Benjamín Carrión”.

Zemelman, H. (1998). Sujeto: existencia y potencia. Barcelona: Anthropos. 